CUADERNOS DE ESTUDIOS GALLEGOS, LIX Núm. 125 (enero-diciembre 2012), págs. 143-156

ISSN: 0210-847 X

DOI: $10.3989 /$ ceg.2012.125.06

\title{
EMIGRACIÓN GALLEGA EN EL SIGLO XVI: EL LINAJE BAHAMONDE EN CHILOÉ
}

\author{
Pablo A. Pérez
}




\section{EMIGRACIÓN GALLEGA EN EL SIGLO XVI: EL LINAJE BAHAMONDE EN CHILOÉ}

\section{RESUMEN:}

El artículo trata acerca de un emigrante gallego venido a Indias en el siglo XVI como integrante de un socorro militar destinado a la Guerra de Arauco. El mismo quedó establecido en la capitanía de Chile, dejando frondosa descendencia en la austral isla de Chiloé -cuyo nombre de conquista fue el de provincia de Nueva Galicia- hasta la actualidad.

Se indican datos históricos sobre el emigrante, así como algunos apuntes genealógicos del tronco del linaje, evidenciando la necesidad de finalizar un estudio ya comenzado años atrás.

En resumen, una contribución a la presencia y herencia de origen gallego fuera de sus fronteras.

Palabras ClaVe: Galicia, Chiloé, genealogía, emigración, Bahamonde-Vaamonde.

\section{EMIGRACIÓN GALEGA NO SÉCULO XVI: A LINAXE BAHAMONDE EN CHILOÉ}

\section{RESUMO:}

$\mathrm{O}$ artigo trata acerca dun emigrante galego vido ás Indias no século XVI como integrante dun socorro militar destinado á Guerra de Arauco. Este quedou establecido na capitanía de Chile, deixando moita descendencia na austral illa de Chiloé -cuxo nome de conquista foi o de provincia de Nueva Galicia- ata a actualidade.

Indícanse datos históricos sobre o emigrante, así como algúns apuntamentos xenealóxicos da liña troncal da liñaxe, evidenciando a necesidade de finalizar un estudo xa comezado anos atrás.

En resumo, unha contribución á presenza e herdanza de orixe galega fora das súas fronteiras.

Palabras CLAVE: Galicia, Chiloé, xenealoxía, emigración, Bahamonde-Vaamonde.

\section{GALICIAN EMIGRATION IN THE $16^{\mathrm{TH}}$ CENTURY: THE LINEAGE BAHAMONDE IN CHILOÉ}

AbSTRACT:

The article discusses about a Galician emigrant who was part of a military troop destined for the War of Arauco. He had established himself in the captaincy of Chile, leaving significant offspring in the southern island of Chiloé -which name of conquest was precisely province of Nueva Galiciauntil today.

It shows historical data on the migrant as well as some genealogical notes about the lineage itself, making evident the need to complete a study that already started some years ago.

In summary, a contribution to the presence and heritage of Galician origin outside its borders.

KEY WORDS: Galicia, Chiloé, genealogy, emigration, Bahamonde-Vaamonde. 
Recibido/Received: 07/03/2012

Aceptado/Accepted: 23/08/2012

\section{EL ENTORNO GALLEGO}

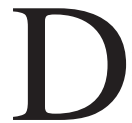
urante el siglo XVI, España tuvo una balanza comercial desfavorable. Esta situación de crisis sufre un iluminador análisis por el burgalés Luis Ortíz, a la sazón contador de Castilla y consejero del rey, quien a poco de iniciado el reinado de Felipe II indica diligentemente los males que pueden resultar del crecimiento excesivo de los precios, de la salida de plata hacia el exterior y del progresivo abandono de los españoles de los oficios manuales en favor de las rentas de juros y tierras. De modo parecido se dirigen al monarca poco tiempo después el intelectual Martín de Azpilcueta y el economista Tomás de Mercado (este último quien, preocupado por la invasión de las mercaderías extranjeras, señala que las mismas terminarían por arruinar la industria nacional, destruyendo "ambas repúblicas, a España y a las Indias")1. La consolidación del poder político y las remesas de plata y oro americano fueron salvando esta situación de crisis².

Desde mediados del siglo XVI la producción de metales preciosos se convirtió en el epicentro de los ingresos de la Monarquía imperial. Sin que significara esto que la Corona pasara a ser productora, por el contrario gravó el sector y los circuitos que generaba con distintos impuestos: los productores de metales preciosos tenían que pagar el quinto, los comerciantes debían cubrir la alcabala en las transacciones internas y el almojarifazgo en las externas. A ello había que sumar los donativos (que en esencia no eran más que contribuciones forzadas) y las aportaciones extraordinarias, exigidas en aquellos momentos en los que por cualquier causa la Corona tenía que realizar un gasto adicional cuantioso al

\footnotetext{
${ }^{1}$ Luis E. Í̃̃IGo Fernández, España. Historia de una nación inacabada, Madrid, Editorial Visionnet, 2005, pág. 206.

${ }^{2}$ Luis Suárez Fernández, Demetrio Ramos Pérez, José Luis Comellas, Andrés Andrés-Gallego, La Crisis de la hegemonía española, siglo XVII, Tomo VIII, Madrid, Ediciones Rialp S.A., 1986, pág. 196.
} 
presupuestado, como por ejemplo las guerras o la defensa de naves cargadas de metales preciosos que regresaban a la Península ${ }^{3}$.

Las cuentas de la Real Hacienda demuestran que, al menos durante el siglo XVI, la Corona gastaba una proporción muy elevada de sus ingresos indianos en suelo americano, al cubrir los altos costos emanados de sus impostergables obligaciones militares (vigilancia de sus costas para impedir el contrabando, construcción de fortalezas y defensa de la paz interna), de sus necesidades administrativas (pago de una extensa maquinaria fiscal y burocrática) y religiosas (evangelización), o realizando lo que en la terminología fiscal actual debiera denominarse pago por compensación (el famoso situado) ${ }^{4}$. Sin embargo, si el gasto público se hizo en su mayor parte en suelo americano, no fue para justificar la función de la Corona al repartir parte de la riqueza tributaria en la población americana en todo su conjunto, sino para fomentar unas específicas relaciones infraestructurales mercantiles que favorecían mayoritariamente a las élites tradicionales (tanto de uno como del otro lado del Atlántico) ${ }^{5}$.

En Galicia (y sobre todo en las ciudades de la costa), donde el comercio fue activo y próspero desde la Edad Media, los efectos de decadencia se sintieron a la larga y con cierto retraso respecto a otras regiones españolas. Desde 1530, con la prohibición imperial de hacer comercio directo con América, los puertos decayeron. Los armadores gallegos autorizados a cargar buques para Indias, debían regresar obligatoriamente por Sevilla, con lo poco ventajoso que esta medida significaba. La prosperidad continuó sin embargo hasta muy avanzado el siglo $\mathrm{XVI}$, quedando la paralización para el siglo XVII'

En la primera mitad del siglo XVI, Galicia experimenta un fuerte crecimiento basado en la roturación de nuevas tierras cultivables y en el comercio atlántico. Se calcula que a partir de 1560 la tierra en Galicia empieza a escasear; y el período de 1585-1607 es de franco estancamiento y de expulsión de campesinos hacia las grandes ciudades del sur. La peste finisecular, de especial incidencia en la costa cantábrica, acentuará el proceso, llevando a vascos y a navarros a dirigirse hacia las vegas aragonesas para cubrir el vacío dejado por los moriscos ${ }^{7}$.

\footnotetext{
3 Pedro Pérez Herrero, La América colonial: 1492-1763. Política y sociedad, Madrid, Síntesis, d.1. 2002, pág. 188.

${ }^{4}$ Pedro Pérez Herrero, Comercio y mercados en América Latina colonial, Madrid, Editorial MAPFRE, 1992, págs. 76 y 77.

5 P. Pérez Herrero, Comercio y mercados ..., pág. 77.

6 Antonio Bonet Correa, La arquitectura en Galicia durante el siglo XVII, Madrid (España), Escélicer, 1966, págs. 9 y 10.

${ }^{7}$ L. SuÁrez Fernández et al., La Crisis de la hegemonía..., pág. 248.
} 
La falta de registros parroquiales y las especiales deficiencias de los censos de 1528-1536 y 1591, dificultan la reconstrucción del movimiento de la población gallega durante el siglo XVI. Si bien se acepta que la población en Galicia aumentó en forma significativa, los comienzos del arranque debieran retrotraerse, cuando menos, a los años finales del siglo XV y primeros del XVI, coincidiendo con el endurecimiento de la política foral de muchos monasterios. Esta tendencia alcista secular será interrumpida por los años de 1580, y la gran etapa expansiva de la demografía gallega tendrá su comienzo para $1630-1640 .^{8}$

Así la situación en Galicia, debe ahora saberse qué sucedía para las mismas fechas, del otro lado del océano.

\section{El Nuevo Mundo}

A pocos años de iniciada la conquista de Chile (en el año 1541), y tras un breve período de exploraciones, el gobernador de este reino D. ${ }^{\mathrm{n}}$ Rodrigo de Quiroga, encomendó a su yerno D. ${ }^{\mathrm{n}}$ Martín Ruíz de Gamboa que emprendiese la conquista del archipiélago de Chiloé. Ésta se concretó en el año 1567, otorgando el conquistador el nombre de provincia de Nueva Galicia al nuevo territorio, fundándose según cuenta el cronista igualmente gallego Pedro Mariño de Lovera, su capital en un asentamiento que tuvo
"por nombre la ciudad de Castro de la nueva Galicia, por respeto del presi- dente Castro gobernador del Perú, que era galiciano; el cual habia proveido a Quiroga por gobernador de Chile, que tambien era gallego como él." 9

Lo cierto es que el nombre de conquista de la provincia le fue dado en homenaje al origen de su suegro ${ }^{10}$; y la primera ciudad fundada tenía por nombre completo el de Santiago de Castro, en honor al apóstol de las Españas y en recuerdo del licenciado santiaguista D. ${ }^{\mathrm{n}}$ Lope García de Castro (entonces presidente de la Real Audiencia de Lima), quien gobernaba interinamente el virreinato del Perú.

\footnotetext{
${ }^{8}$ Alberto Marcos Martín, España en los siglos XVI, XVII y XVIII, Barcelona (España), Editorial Crítica, S.L.; Caja Duero, 2000, pág. 334.

9 Pedro Mariño de Lovera, Crónica del Reino de Chile. Colección de Historiadores de Chile y documentos relativos a la Historia Nacional, volumen VI, Santiago (Chile), Imprenta del Ferrocarril, 1865, pág. 307.

${ }^{10}$ Claudio GAY, Historia física y política de Chile, tomo II, París, Imprenta de Fain y Thunot, 1845, pág. 28.
} 
Este archipiélago de Chiloé tiene algo más de $9.000 \mathrm{~km}^{2}$, y una multitud de islas diseminadas por el sector oriental, de cara al continente americano. Fue un importante enclave español en el tiempo colonial, ya que era paso obligado de los navíos que iban y venían al estrecho de Magallanes, y sufrió por ello repetidos ataques corsarios a lo largo de su historia.

La zona de análisis sufrió un extremo aislamiento (político, social, cultural, etc., amén del geográfico) respecto de Chile, ya que sólo mantenía un esporádico contacto vía marítima con el Perú; y ello además una serie de diversos factores (como las etnias locales, las características geográficas y ecológicas del lugar, etc.) es causa de que se haya desarrollado una cultura muy típica y con características únicas en el mundo, que mezcló, adaptó y creó diversos elementos, y que le dio en definitiva identidad a éste pueblo. Una cultura donde se mantienen y perviven tradiciones antiguas (faenas rurales; molinos hidráulicos; música de ritmos antiguos; un gran sentido de religiosidad, que fue el que generó la llamada "Escuela Chilota de Arquitectura Religiosa en Madera”, y que es causa del nombramiento por la UNESCO de algunas iglesias de Chiloé como "Patrimonio de la Humanidad"; etc.), donde subsisten arcaísmos castellanos diariamente, etc. Las relaciones de parentesco entre las familias tradicionales de la colonia adquirieron en este lugar características particulares también.

Chiloé destaca también dentro el aspecto histórico, en la época donde se forman los modernos países americanos que intentan independizarse de España. Así, la isla fue el último bastión español en toda América del Sur, hasta el año 1826 donde, tras tres intentos por parte de Chile de anexionar el territorio, pierden las tropas reales.

\section{EL EMIGRANTE}

El principio de la casa se encuentra en Ribadeo, donde es nacida Constanza López de Bahamonde quien luego casa con Sancho Méndez de Abrana. Un hijo de este matrimonio migra luego a América, generando el vínculo a los Bahamonde actuales.

Su linaje lleva un apellido gallego que acostumbra a usar las formas Bamonde, Baamonde, Bahamonde, Vaamonde, etc. En su inicio fue unido a patronímicos, y puede ser rastreado hasta el primer tercio del 1500 en el norte peninsular, si bien por varonía se trata de una ascendencia proveniente del precioso y pintoresco pueblo de Chinchón, ubicado en el valle del Tajuña.

Viajar al Nuevo Mundo era para muchos una novedad, para muchos una oportunidad, y para otros una necesidad. El personaje considerado viajó por 
propia voluntad; y se explicará seguidamente qué hechos se sucedían en aquel entonces en América.

En el siglo XVI en Chile se vivía plenamente la llamada Guerra de Arauco, equiparada al frente de Flandes. Las ciudades eran atacadas por los indígenas sublevados y muertos sus habitantes en las guerrillas, y la inseguridad era cosa de todos los días.

Por su fracaso en la administración civil y militar, el entonces gobernador de Chile D. ${ }^{\mathrm{n}}$ Melchor Bravo de Saravia ofreció su dimisión al rey, con pretexto de su edad avanzada. Antes que el monarca tomase alguna resolución sobre el particular, el virrey del Perú designó a Rodrigo de Quiroga como capitán general o director en jefe de las operaciones militares, y a Bernal de Mercado como maestre de campo. Aun cuando el primero no aceptó esta comisión por considerarse rebajado con ella después de haber sido gobernador, el desprestigio de Bravo de Saravia llegó a su último extremo. Por fin, en 1573 el rey aceptaba su renuncia y nombraba en su lugar a Rodrigo de Quiroga, agraciado además en igual fecha con el hábito de caballero de la orden de Santiago. Suprimió igualmente la Real Audiencia y ordenó que el capitán Juan de Losada formase en España y América un cuadro de cuatrocientos soldados para la guerra de Arauco ${ }^{11}$. Existe una Real Cédula relacionada a este refuerzo militar (de fecha 12/12/1574) ${ }^{12}$.

En noviembre de 1574 se supo en Santiago el nombramiento de Quiroga. El vecindario

\begin{abstract}
"lo recibió con unánime aceptación i regocijo, porque Bravo de Saravia se habia atraído el rencor popular por su mala suerte, su avaricia privada i su avidez insaciable para "recojer oro"." 13
\end{abstract}

Poco tiempo después llegaron las cédulas reales " $i$ el 26 de enero de 1575 prestaba el nuevo gobernador ante el cabildo el juramento solemne que era usual" 14 , comenzando así el segundo de sus gobiernos.

Diego de Rosales, aunque un poco sesgado de las fechas mencionadas, aporta más informaciones al relatar:

\footnotetext{
11 Universidad de Chile, Anales de la Universidad de Chile, Santiago (Chile), Imprenta Cervantes, 1901, págs. 39-40.

12 Andrés Huneeus Pérez, Historia de las polémicas de Indias en Chile durante el siglo XVI, 15361598, Facultad de Ciencias Jurídicas y Sociales, Universidad de Chile, Santiago (Chile), Editorial Jurídica de Chile, 1956, pág. 98.

13 Universidad de Chile, Anales de la..., pág. 40.

14 Universidad de Chile, Anales de la..., pág. 40.
} 
"El verano siguiente, que fue el del año de 1576, le embio su Magestad al Gobernador Rodrigo de Quiroga quatrocientos y ochenta hombres de socorro de España, y le honro con un abito de Santiago y con renta, por las noticias, que tubo de sus muchos meritos y grandes seruicios en este Reyno. Traxo estos soldados el General Juan de Losada a su cargo, hasta la Isla de la Dominica, donde fallecio, y alli se entrego de ellos el Capitan Juan Lozano Machuca, secretario, que fue del Duque de Vexar, y oficial Real de Potosí. Gobernolos hasta meterlos en la ciudad de los Reyes, donde el Virrey proueyó otra cosa. Los Capitanes eran todos viexos, y que abian militado con mucho nombre en Flandes, y de verlos reciuio este Reyno mucho contento. Fueron el Maestro de Campo Andrés de Molina, que traxo la gente a cargo por ser noble, y de mucha estimacion por sus grandes seruicios en la guerra. Juan Martinez Palomeque Sargento Mayor de la misma tropa, el Capitan Jusepe de Castro, Juan de Nodal, Andres Ibañes de Barrueta, Don Antonio Faxardo, y otros que se reformaron en Lima por seguir nuevas pretensiones." 15

En este contingente de Juan de Losada se encontraba a su costa Fernando Álvarez de Bahamonde ${ }^{16}$, el fundador de su linaje en Chiloé.

En la actualidad, la estirpe posee varias ramas -perfectamente identificadas-, llevando algunos de sus integrantes el apellido Bahamonde y otros el Álvarez; mientras que otros todavía permanecen sin ser filiados ${ }^{17}$.

$$
* * *
$$

\footnotetext{
${ }^{15}$ Diego de Rosales, Historia general de Chile, Flandes indiano, tomo I, Santiago (Chile), Editorial Andrés Bello, 1989, pág. 592.

16 Luis de Roa y Ursúa, El Reyno de Chile. 1535-1810, Valladolid, Consejo Superior de Investigaciones Científicas; Instituto "Jerónimo Zurita", Sección de Historia Moderna "Simancas", 1945, pág. 441, núm. 1739.

17 Pablo A. Pérez, "Álvarez en Chiloé, o una rama genealógica no filiada del linaje Bahamonde", Revista de Estudios Históricos, Año LIX, 52 (2010), págs. 215-276.
} 
La tabla genealógica resumida del linaje es ${ }^{18}$ :

I. Sancho Méndez de Abrana. Bautizado en la feligresía de Grandas (concejo de Castropol, Asturias). Casado cerca de 1550 con Constanza López de Bahamonde (nacida alrededor de 1530 en Ribadeo; descendiente de la casa de su apellido).

II. Fernando Álvarez de Bahamonde (también llamado Fernando Bahamonde), primero de su nombre en el linaje. Nacido alrededor de 1555 en Grandas; venido a la guerra de Arauco en la expedición de Juan de Losada (1575); capitán; encomendero en 1595; produjo información sobre su hidalguía (1597 en Osorno); depositario general de la ciudad y vecino de Osorno, hasta su despueble en 1600; vecino de Santiago de Chile; procurador síndico y mayordomo de la ciudad (septiembre del 1600); con casas principales frente al palacio del obispo. Falleció en la estancia de Codegua, a la otra banda del río Maipo; al atravesar dicho río había perdido su documentación. Fue casado dos veces: la primera, en Osorno, con D. ${ }^{a}$ Ana de Ocampo; y la segunda vez, previa escritura de dote ante Ginés de Toro, por 5000 pesos de oro de contrato, de 201/2 quilates, en solares, chacras y otros efectos (19/1/1596 en Santiago de Chile) con D. ${ }^{a}$ Beatriz de Guzmán (hija legítima de Andrés Sánchez de Fuenzálida, natural de Torrijos, vecino encomendero de Cañete, y de D. ${ }^{a}$ Ana de Guzmán). Con descendencia tanto del primero (a) como del segundo (b) de sus enlaces:

1a) D. ${ }^{a}$ Teresa de Bahamonde, quien sigue la línea.

2b) Jerónimo de Bahamonde. Nacido en 1604 en Santiago de Chile; fallecido el $1 \% / 9 / 1664$, después de haber profesado in articulo mortis de la Compañía de Jesús; asistente a la Guerra de Arauco; dueño de estancias de Nilagüe y Reto. Casado con D. ${ }^{a}$ María Verdugo de Sarria (natural de Osorno; hija legítima de Rodrigo Verdugo Pasillas, sargento mayor del reino, corregidor de Osorno, y de D. ${ }^{\mathrm{a}}$ Leonor de la Corte). Con sucesión natural de Juana de Puebla, ascendientes de la casa del condado de Maule.

\footnotetext{
18 Juan Luis EsPejo, Nobiliaria de la antigua capitanía general de Chile, tomo I, Santiago (Chile), Imprenta Universitaria, 1917, págs. 56 y 57; Alberto GarCía CARRAFFA, Arturo GarCía CARRAFFA, Diccionario heráldico y genealógico de apellidos españoles y americanos, Tomo XIII, Madrid, Imprenta de Antonio Marzo, 1923, págs. 52 y 53; L. DE ROA Y URSÚA, El Reyno de... pág. 441, núm. 1739; Gabriel Guarda O.S.B., La sociedad en Chile austral antes de la colonización alemana, 1645-1845, Santiago (Chile), Editorial Andrés Bello, 1979, pág. 182; José Santiago CRESPO DEL Pozo, Blasones y linajes de Galicia, tomo I, Pontevedra, Publicaciones del Monasterio de San Juan de Poyo, 1982, pág. 147; Endika De Mogrobejo, Diccionario Hispanoamericano de Heráldica, Onomástica y Genealogía, vol. XXIX (IX), Bilbao, Editorial Mogrobejo-Zabala, 1995-1998, págs. 160-161; G. GuARDA O.S.B., Los Encomenderos de Chiloé, Santiago, Ediciones Universidad Católica de Chile, 2002, págs. 100, 101, 177.
} 
3b) Antonia Bahamonde, primera así llamada en su linaje. Casada con Luis de Ulloa (natural de Tordesillas; capitán).

III. D. ${ }^{\text {a }}$ Teresa de Bahamonde. Natural de Osorno. Casada con Pedro González de la Hoz (capitán de Infantería; vecino de Castro en 1580; defensor cuando el pirata en el 1600; presente con sus armas y caballos en la revista general de la Provincia convocada por el general D. ${ }^{\mathrm{n}}$ Jerónimo de Peraza, en 1614; sargento mayor de Chiloé; encomendero en segunda vida de los pueblos que fueron de su padre, desde 1604; hijo de Luis González -natural de Chinchón- y de una hermana de Rodrigo de Bastidas). Ambos son autorizados para pasar a Concepción. Con los siguientes hijos conocidos:

1) Fernando Álvarez de Bahamonde, quien sigue la línea.

2) el licenciado Luis González de la Hoz. "Capellán, Cura y Vicario de la gente de guerra que milita en la provincia de Chiloê".

3) el licenciado Juan Pérez de Ocampo. Natural de Chiloé; es ordenado antes de 1633; y se encuentra presente en Santiago de Chile (1635).

IV. Fernando Álvarez de Bahamonde, el segundo de su nombre. Vecino de Chiloé; capitán del fuerte de San Miguel de Calbuco; regidor y alcalde de la ciudad de Santiago de Castro; encomendero en primera vida de Cuduguita, Dallico, Tengachao, Lemuy, Terao y Payos. Fue casado con D. ${ }^{a}$ Gregoria Barrientos (encomendera del pueblo de Chauques, con dieciocho tributarios, por merced de 1683, y de los indios sin pueblo, por merced del año 1694; hija legítima de de D. ${ }^{\mathrm{n}}$ Andrés Vásquez de Barrientos y de D. ${ }^{\mathrm{a}}$ Ana de Montenegro). Se sabe que el matrimonio tuvo seis hombres y seis mujeres (según una declaración del año 1694); de los cuales se conocen en este momento a:

1) D. ${ }^{n}$ Fernando Álvarez de Bahamonde, quien sigue la línea.

2) D. ${ }^{\mathrm{n}}$ Alonso de Bahamonde, primero de su nombre en el linaje. Capitán de infantería; teniente de veedor; alférez real; regidor; alcalde y corregidor de Santiago de Castro; encomendero por merced del presidente González Montero (16/10/1670), cuya encomienda es declarada vaca por defecto de confirmación (20/12/1683); encomendero de Lemuy por merced (20/12/1684 en Concepción), vacante por falta de confirmación (5/11/1693); feudatario del pueblo de Palqui por merced (1\%/10/1694 en Santiago de Chile). Casado con D. ${ }^{a}$ Mencía de Tapia. Con descendencia.

3) D. ${ }^{a}$ Gregoria Bahamonde. Encomendera de la encomienda llamada de Cárcamo, o sin nombre (por merced 2/9/1694), así como de la de Chauques (por merced del 17/12/1783). Casada con D. ${ }^{n}$ Diego 
Díaz de Alvarado (natural de las montañas de Burgos). Con descendencia.

4) quizá, Lorenzo Álvarez de Bahamonde. Capitán de Calbuco; teniente de veedor; dos veces alcalde; corregidor de Castro; encomendero de Lemuy (por título del 20/12/1684).

V. D. ${ }^{\mathrm{n}}$ Fernando Álvarez de Bahamonde, el tercero de su nombre. Capitán de San Antonio de Chacao; litiga sus derechos a la herencia de D. ${ }^{\mathrm{n}}$ Fernando Álvarez de Bahamonde y de D. ${ }^{a}$ Beatriz de Guzmán (1666). Fue casado con D. ${ }^{a}$ Inés de Godarte; y aparentemente también el mismo casado con D. ${ }^{a}$ María de Villegas (administradora de la encomienda de Quenac en 1724; hija legítima de D.n Miguel Villegas y de D.a Margarita Cárcamo). Con descendencia tanto de la primera (a) como de la segunda (b) de sus dos uniones en:

1a) D. ${ }^{\mathrm{n}}$ Luis Álvarez de Bahamonde, también llamado Luis Álvarez (1740). Fallecido antes de 1724. Quien sirvió por más tiempo de 30 años a su costa, con armas y caballos; capitán; efectuó tres viajes al Archipiélago de los Chonos, en la última donde fue por cabo de diez hombres; encomendero de Quenac. Casado con D. ${ }^{a}$ María Villegas. Con descendencia.

2b) D. ${ }^{\mathrm{n}}$ Fernando Bahamonde, quien sigue la línea.

VI. D.n Fernando Bahamonde. Capitán del Regimiento de la Nobleza; apoderado de Bartolomé Vázquez de Barrientos Maldonado (noviembre de 1607); oponente a la vacante del pueblo de Cuduguita (1707). Fue casado con D. ${ }^{\text {a }}$ Isabel Díaz. Se le conocen varios hijos, quienes han generado descendencia hasta la actualidad.

\section{Consolidación Del LinAJE}

Si bien ya en los primeros tiempos de asentamiento blanco se fundaron algunas villas, la principal característica de los habitantes de Chiloé a lo largo de su historia ha sido la vida en dispersión; es decir, habitando los distintos parajes e islas que componen al archipiélago. Esto llevó a los misioneros jesuitas y más tarde a los franciscanos, a recorrer la provincia evangelizando en la llamada “misión circular", que llevó a levantar iglesias en muchos lugares donde comenzaron a nacer poblados a orillas de la costa.

El aislamiento contribuyó a la mantención de las tradiciones locales y familiares, donde la reciprocidad y el trabajo comunitario fueron el vínculo entre los miembros de la sociedad. Empero, en las distintas zonas que componen Chiloé hubieron familias que se caracterizaron por ser extensas y mayoritarias (como los García en la isla de Linlín; los Bórquez, Vera, o Andrade en Chonchi; los 
Oyarzún y Soto en Curaco de Vélez; los Pérez, Gallardo, Díaz, o Arroyo en Dalcahue; etc.), indicando que los parentescos genealógicos en la Isla de Chiloé son fundamentalmente los de cruzamientos entre individuos de una misma comunidad y origen, y encontrando las causas de ello en una antigua usanza del tiempo de la conquista y colonia.

El caso de los Bahamonde es emblemático en la comarca de Dalcahue donde, además de alcanzar un gran número, destacan por el sostenimiento de sus tradiciones (religiosidad, música, canto y baile, carpintería de ribera, marinería, enseñanza escolar, etc.). También, hay miembros de esta familia que han sido personajes importantes no sólo para Chiloé sino que han logrado trascendencia nacional.

La endogamia tiene un fuerte peso en Chiloé. Un claro ejemplo de ello puede ser el matrimonio entre Pedro Antonio Bahamonde (hijo legítimo de Justo Bahamonde y de María Andrea Bahamonde), quien es casado en 1852 en la parroquia de Tenaún ${ }^{19}$ con María Guía Bahamonde (hija natural de José del Carmen Bahamonde y de María Cruz Bahamonde). Pedro Antonio Bahamonde es por su padre cuarto nieto de D. ${ }^{\mathrm{n}}$ Fernando Bahamonde y de D. ${ }^{\mathrm{a}}$ Isabel Díaz (mencionados en VI. de la tabla anterior), aunque bisnieto del mismo matrimonio por su madre. Del mismo modo, su esposa María Guía Bahamonde es igualmente cuarta nieta de dicho matrimonio por línea agnaticia, así como quinta nieta por línea materna (por ser María Cruz Bahamonde hija natural de María Ramona Bahamonde, esta última quien además era casada legítimamente con José Domingo Bahamonde).

El menor de los hijos de Pedro Antonio Bahamonde y de María Guía Bahamonde fue José Secundino Bahamonde, en cuyo bautizo en 1860 en Tenaún consta por madrina María Jacoba Bahamonde junto a su esposo ${ }^{20}$. Al confirmarse José Secundino Bahamonde, cinco años más tarde de su bautizo, el padrino de este sacramento es... Fortunato Bahamonde ${ }^{21}$.

Este recurso y hábito endogámico, muy común en las sociedades pasadas, tenía gran importancia como elemento de autoperpetuación en tanto que permitía mantener las señas de una identidad y afianzar a una comunidad en su estrato social.

Los chilotes en general (y los Bahamonde entre ellos) se dispersaron no sólo por el archipiélago de Chiloé, sino también por el sur americano (Magallanes, la Patagonia), la zona central de Chile, etc.

\footnotetext{
${ }^{19}$ LMT2, foja $36, \mathrm{~N}^{\circ} 156$.

${ }^{20}$ LBT3, foja $158, \mathrm{~N}^{\circ} 531$.

${ }^{21}$ LCT* $^{*}$, foja 4.
} 


\section{NECESIDAD DE UN ESTUDIO}

Los estudios genealógicos poseen una importancia de especial significación e interés, por el contenido histórico y la dinámica social que involucra a una región, y las relaciones que de estas exposiciones se desprenden.

Es escasa la bibliografía existente sobre genealogías de Chiloé, y ha surgido hace años la necesidad de realizar un proyecto de recuperación histórica y genealógica de este linaje, típico y característico incluso de Chiloé. Además, nunca se hizo ningún estudio específico al respecto del linaje Bahamonde, un abolengo cuyos integrantes filiados alcanzan en Chiloé hasta el año 1900 alrededor de unas 2.000 personas. Hoy, a 436 años del pasaje a Indias de su fundador, se hace aún más evidente contar con una obra de referencia en el tema.

La importancia de esta iniciativa va de la mano con la estimulación de la recuperación de este pasado histórico, cultural y genealógico local de Chiloé, dirigiéndose básicamente a los habitantes de Galicia y Chiloé en general, y a las más jóvenes generaciones en particular, para despertar en ellos el interés por su origen y la revalorización de su cultura.

Este tratado monográfico en curso es también sumatoria de elementos de patrimonio intangible de origen gallego, tendiente a recuperar y revalorizar este acervo y herencia, rescatando el pasado histórico y genealógico de un linaje de origen galaico, asentado en la colonia más austral de la corona española en América. Su estudio reviste especial importancia, considerando su amplia antigüedad, su dispersión, y su significación social.

Esta iniciativa no tiene adscripción institucional alguna, y su finalización está condicionada al acceso a algunas informaciones faltantes; por lo que se espera pronto poder concluirlo en el menor tiempo posible.

\section{DOCUMENTACIÓN}

Las siglas utilizadas en este escrito se corresponden con la siguiente documentación:

LBT3: Portada: "Libro en que se acien / tan las partidas de oleo / y crisma que principia / el dos del mes de Octu / bre del año de 1850. / Parroquia de Tenaun / Fr. Bernardino Cárcamo". Tapa: "3\% / Libro $3^{\circ}$ de Bautismos [y] / oleos / 1850 a 1861=".

LCT*: Portada: "Cuaderno de Confirmaciones de hombres"; y en foja 12: "Cuadernos de Confirmacion de / _-_mujeres_-_-". Sin leyenda en la tapa ni en el lomo. Las hojas $8 \mathrm{v}, 9,9 \mathrm{v}, 10,10 \mathrm{v}, 11$ y $11 \mathrm{v}$ están en blanco.

LMT2: Portada: "Libro en que se sientan las parti= / das de Casamientos que principia / el dia diez y seis del mes de Sep. = / tiembre del añode mil ocho= / cientos cuarenta y nuebe // Parroquia de Tenaun. siendo cura el R. P. Fr. Anjel Anfossi. / [firmado:] Fr. Anjel Anfossi"'. Tapa: "-2 / Libro $2^{\circ}$ de matrimonios / 1849:". 


\section{BIBLIOGRAFÍA}

Bonet Correa, Antonio, La arquitectura en Galicia durante el siglo XVII, Madrid, Escélicer, 1966.

Crespo del Pozo, José Santiago, Blasones y linajes de Galicia, tomo I, Pontevedra, Publicaciones del Monasterio de San Juan de Poyo, 1982.

Espejo, Juan Luis, Nobiliaria de la antigua capitanía general de Chile, tomo I, Santiago (Chile), Imprenta Universitaria, 1917.

García Carraffa, Alberto; García Carraffa, Arturo, Diccionario heráldico y genealógico de apellidos españoles y americanos, Tomo XIII, Madrid, Imprenta de Antonio Marzo, 1923.

Gay, Claudio, Historia física y política de Chile, tomo II, París, Imprenta de Fain y Thunot, 1845.

Guarda O.S.B., Gabriel, La sociedad en Chile austral antes de la colonización alemana, 1645-1845, Santiago (Chile), Editorial Andrés Bello, 1979.

Guarda O.S.B., Gabriel, Los Encomenderos de Chiloé, Santiago (Chile), Ediciones Universidad Católica de Chile, 2002.

Huneeus Pérez, Andrés, Historia de las polémicas de Indias en Chile durante el siglo XVI, 1536-1598, Facultad de Ciencias Jurídicas y Sociales, Universidad de Chile, Santiago (Chile); Editorial Jurídica de Chile, 1956.

Íñigo Fernández, Luis E., España. Historia de una nación inacabada, Madrid, Editorial Visionnet, 2005.

Marcos Martín, Alberto, España en los siglos XVI, XVII y XVIII, Barcelona, Editorial Crítica, S.L.; Caja Duero, 2000.

Mariño de Lovera, Pedro, Crónica del Reino de Chile. Colección de Historiadores de Chile y documentos relativos a la Historia Nacional, vol. VI, Santiago (Chile), Imprenta del Ferrocarril, 1865

Mogrobejo, Endika de, Diccionario Hispanoamericano de Heráldica, Onomástica y Genealogía, vol. XXIX (IX), Bilbao, Editorial Mogrobejo-Zabala, 1995-1998.

Pérez, Pablo A., "Álvarez en Chiloé, o una rama genealógica no filiada del linaje Bahamonde", Revista de Estudios Históricos, Año LIX, núm. 52 (2010), págs. 215-276.

Pérez Herrero, Pedro, Comercio y mercados en América Latina colonial, Madrid, Editorial MAPFRE, 1992.

Pérez Herrero, Pedro, La América colonial: 1492-1763. Política y sociedad, Madrid, Síntesis, d.1. 2002.

Roa y Ursúa, Luis de, El Reyno de Chile. 1535-1810, Valladolid. Consejo Superior de Investigaciones Científicas; Instituto "Jerónimo Zurita", Sección de Historia Moderna "Simancas", 1945.

Rosales, Diego de, Historia general de Chile, Flandes indiano, Tomo I, Santiago (Chile), Editorial Andrés Bello, 1989.

Suárez Fernández, Luis; Ramos Pérez, Demetrio; Comellas, José Luis; Andrés-Gallego, Andrés, La Crisis de la hegemonía española, siglo XVII, Tomo VIII, Madrid, Ediciones Rialp, S.A., 1986.

Universidad de Chile, Anales de la Universidad de Chile, Santiago (Chile), Imprenta Cervantes, 1901. 